\title{
A hybrid model integrating FMEA and HFACS to assess the risk of inter-city bus accidents
}

\author{
James J. H. Liou ${ }^{1} \cdot$ Perry C. Y. Liu ${ }^{2} \cdot$ Shiaw-Shyan Luo ${ }^{3} \cdot$ Huai-Wei Lo ${ }^{4}$ (D) Yu-Zeng Wu ${ }^{1}$
}

Received: 30 June 2021 / Accepted: 17 January 2022 / Published online: 8 February 2022

(c) The Author(s) 2022

\begin{abstract}
The incidence of inter-city bus accidents receives a lot of attention from the public because they often cause heavy casualties. The Human Factors Analysis and Classification System (HFACS) is the prevailing tool used for traffic accident risk assessment. However, it has several shortcomings, for example: (1) it can only identify the potential failure modes, but lacks the capability for quantitative risk assessment; (2) it neglects the severity, occurrence and detection of different failure modes; (3) it is unable to identify the degree of risk and priorities of the failure modes. This study proposes a novel hybrid model to overcome these problems. First, the HFACS is applied to enumerate the failure modes of inter-city bus operation. Second, the $Z$-numberbased best-worst method is used to determine the weights of the risk factors based on the failure mode and effects analysis results. Then, a $Z$-number-based weighted aggregated sum product Assessment is utilized to calculate the degree of risk of the failure modes and the priorities for improvement. The results of this study determine the top three ranking failure modes, which are personal readiness from pre-conditions for unsafe behavior, human resources from organizational influence, and driver decision-making error from unsafe behavior. Finally, data for inter-city buses in Taiwan in a case study to illustrate the usefulness and effectiveness of the proposed model. In addition, some management implications are provided.
\end{abstract}

Keywords Failure mode and effects analysis (FMEA) - Human Factors Analysis and Classification System (HFACS) . $Z$-number-based best-worst method $(Z$-BWM $) \cdot Z$-number-based weighted aggregated sum product assessment $(Z$-WASPAS)

\section{Introduction}

Huai-Wei Lo

w110168888@gmail.com

James J. H. Liou

jamesjhliou@gmail.com

Perry C. Y. Liu

perryliu@hotmail.com

Shiaw-Shyan Luo

aluo@mail.tku.edu.tw

Yu-Zeng Wu

t107378020@ntut.org.tw

1 Department of Industrial Engineering and Management, National Taipei University of Technology, Taipei, Taiwan

2 Program at College of Management, National Taipei University of Technology, Taipei, Taiwan

3 Department of Transportation Management, Tamkang University, New Taipei City, Taiwan

4 Department of Business Administration, Chaoyang University of Technology, Taichung, Taiwan
Accidents are occurring more and more frequently due to the continuous and rapid development of road traffic, causing an increase in the numbers of injuries and fatalities each year [48]. According to the "Global Plan for the Decade of Action for Road Safety 2011-2020" released by the World Health Organization, the annual global death toll caused by road traffic related collisions is nearly 1.25 million [55]. Moreover, traffic accidents have become the third leading cause of death worldwide [32]. From an economic point of view, the losses caused by traffic accidents account for about $3 \%$ of the Gross Domestic Product (GDP) of low- and middle-income countries [55]. Road transportation is a complex and open system, which is affected by many factors such as the environment, infrastructure, hardware, software, human factors, and their interaction.

In European countries, safety management action has been implemented through Safety Management Systems (SMS) since the 1970s. The concepts in SMS cover the managerial actions for all accidental risks to life, health, property and the 
environment [15]. Li and Guldenmund [29] pointed out that new technologies, audit tools and standard procedures have been developed to improve the SMS over the past 20 years. There are also several other widely used risk management models, including the Systems-Theoretic Accident Model and Processes (STAMP) developed by Newnam and Goode [34], the Haddon matrix [51], Human Factors Analysis and Classification System (HFACS) [45], and many others.

In recent years, many studies have focused on the use of HFACS for transport system risk assessment and management studies that have proved its effectiveness and reliability. This model describes the four levels of human negligence, namely "unsafe behavior," "preconditions for unsafe behavior," "unsafe supervision," and "organizational influence." Reinach and Viale [41] improved the original framework and introduced a fifth aspect, "external factors," as the highest level to optimize the relevant failure modes within the entire framework. The advantage of HFACS is that it can actively track the causes of accidents and find and determine the root cause of hazardous events. In addition, the model can effectively and reasonably analyze the human factors in system problems as they happen. It provides a wider range of theoretical and methodological support for accident analysis and prevention in safety science. This model has been widely used in various fields for the analysis of natural gas pipelines [53], chemical storage [43], and mining safety [27]. In regards to road safety, Zhang et al. [56] explored the causal relationships between traffic accident factors, and discussed the interaction between the various HFACS levels to establish a systematic assessment method. Their results showed "unsafe behavior" to be the most frequent failure mode in road accidents. The priorities for accident categories are rollover, leaks, fire, explosion, and collision. Zhang et al. [55] also identified "unsafe behavior" as one of the most important failure modes for traffic accidents. After a review of many bus accidents they found the four most important human factors to be "organizational process," "insufficient supervision," "personal readiness," and "violations." Obviously, there are multiple paths which can lead to failure while passing through from the bottom to the top level, which is a strong implication of the interdependence between the various human factors.

Although HFACS is a useful tool to explore the possible failure modes in risk analysis, it is still insufficient when used alone for road accident analysis. First, it can only identify the potential failure modes, because of the lack of quantitative risk assessment techniques [55]. Second, it does not consider the severity, occurrence or detection of the different failure modes [26]. Third, it is unable to identify or prioritize the risk degree of the failure modes. Therefore, this study proposes a novel multi-criteria decision-making (MCDM) based risk assessment model for the improvement of road traffic safety, especially in relation to inter-city bus traf- fic. The model uses HFACS to identify the potential failure modes of road accidents. Failure mode and effects analysis (FMEA) is then applied to the proposed risk factors, including severity $(S)$, occurrence $(O)$, detection $(D)$, and expected cost $(E)$, to review the potential failure modes and obtain a risk assessment matrix. Many novel FMEA models include $E$ as a practical risk factor, which reflects the necessity of resource allocation [31, 32].

Finally, the $Z$-number-based best-worst method ( $Z$ $\mathrm{BWM}$ ) is used to determine the weights of the risk factors, and $Z$-number-based weighted aggregated sum product assessment (Z-WASPAS) is applied to calculate the risk degree of the potential failure modes. The experts' judgements integrated by using the $Z$-number method are necessary applied to estimate the failure modes because there are insufficient data to estimate the severity, occurrence and so on for most of the failure modes. The $Z$-number allows one to effectively integrate the uncertain or vague information of the experts' judgements. The $Z$-number-based analytic hierarchy process ( $Z$-AHP) requires an excessive number of pairwise comparisons and has poor consistency but $Z$-BWM improves these problems. In addition, the calculation process of $Z$ WASPAS is easier to understand and carry out than either the $Z$-number-based VIseKriterijumska Optimizacija I Kompromisno Resenje ( $Z$-VIKOR) or $Z$-number-based technique for order preference by similarity to ideal solution (Z-TOPSIS). $Z$-WASPAS also includes the concept of the Risk Priority Number (RPN) found in the original FMEA calculation. The proposed model identifies potential failure modes for every aspect and prioritizes the risk of failure modes in road traffic accidents. Finally, a case study based on data for inter-city bus traffic in Taiwan is carried out as an empirical example and managerial implications are provided. The specific contributions and characteristics of this research are summarized below.

1. This study develops a novel risk assessment model, which uses HFACS to summarize the potential failure modes for inter-city bus transportation.

2. The risk factors for assessment are determined based on FMEA theory, to obtain the $S, O$, and $D$. In addition, considering the actual situation of resource constraints, a fourth risk factor, " $E$ " is added.

3. Z-numbers are used to reflect the uncertainty and confidence level of the experts' risk assessment responses.

4. Z-BWM is used to overcome the problem of too many pairwise comparisons required by classic analytic hierarchy process method.

5. Z-WASPAS is used to calculate the risk level of the failure modes and decide the priorities for improvement.

6. An empirical case study of an inter-city bus system in Taiwan is carried out to help understand the practical implications. 
The rest of the paper is organized as follows. "Literature review" gives a brief review of recent related FMEA and HFACS studies, and points out gaps in the research in this field. The calculation processes for HFACS, FMEA, $Z$-BWM and $Z$-WASPAS used in this study are described in "The proposed hybrid model". In "Illustration in a real case study", the inter-city Taiwan bus system used to illustrate the proposed model is outlined. Some theoretical and practical implications are discussed in "Discussion". Finally, a summary of the findings, contributions of this research, and future research directions is included in "Conclusions and future work".

\section{Literature review}

\section{Road traffic safety and accidents}

Road transport is comprised of a complex system involving personnel, vehicles, roadways, and the surrounding environment. To effectively reduce risks in such a complex system, it is necessary to have a thorough understanding of the various factors that lead to traffic accidents, for instance, the design of vehicles, roads and traffic systems, driving regulations, as well as road and vehicle maintenance. Peden et al. [38] pointed out that the most common causes of traffic accidents arise from infrastructure, environmental, vehicular and human factors. Stanton and Salmon [46] argued that there is no effective structured method for assessing the effect of human error in road transportation accidents. An effective system for accurate classification of various causative factors is also lacking, although they found that human error and driving behavior errors triggered about $75 \%$ of traffic accidents. Di Pasquale et al. [12] found human error-related factors to be the cause of about $60-90 \%$ of accidents in the road transport system, with the remaining accidents being attributable to technical defects. Thus, about $85 \%$ of road transport accidents are caused by human error.

Numerous studies exploring the causes of traffic accidents have appeared in the literature. According to Laaraj and Jawab [22], the current methods can be divided into two categories: traditional and systematic. Traditional methods mainly focus on exploring human factor errors, such as the driver's personality traits, driving while fatigued, and deviations in driving behavior. Beanland et al. [6] analyzed responses to driver behavior questionnaires to uncover the personality traits that lead to abnormal driving behaviors. Jiang et al. [20] used detailed statistical data from 45 serious traffic accidents to sort out key error factors in terms of "direct cause", "type of accident", and "accident responsibility", which included "speeding", "improper driver operation", "vehicle overload", "fatigue driving", and "bad driving habits." The traditional methods focus on driver error, but this perspective might be too narrow to analyze the multidimensionality and complexity of a transportation system.

Systematic methods, on the other hand, consider overall factors (e.g., environmental, human or machine) and their interaction within the road system. These methods include the accident map (Accimap) [39], cognitive reliability and error analysis method (CREAM) [47], HFACS [50], STAMP [23], etc. System analysis models are more suitable than traditional methods for understanding problems in the real world. However, both types of methods show that human factors, especially driving behavior, are the key cause of road traffic accidents. Thus, a comprehensive analysis of the effect of human factors in the system is crucial.

\section{HFACS}

HFACS was developed for the classification of human errors. It was originally proposed by Shappell and Wiegmann [45] as a tool for investigating human factors and database classification structure. It was mainly used by the US military to investigate and analyze the human causes of aviation accidents at that time. The causality framework for human caused accidents proposed by Reason [40] used in this framework is based on the identification of "active failures" and "latent failures" in human error (the so-called Swiss cheese model of human error) distilled into four levels, namely, "unsafe behavior," "preconditions for unsafe behavior," "unsafe supervision," and "organizational influence" [50].

The HFACS model has been adapted to make it more suitable for application in different circumstances, such as for the investigation of errors in railway, sea freight, healthcare, mining, and construction settings, to name a few. HFACS has been combined with other methods for risk analysis as a means to remedy the shortcomings of traditional human error identification methods. For example, Celik and Cebi [8] combined the Fuzzy AHP with HFACS to analyze the human factors leading to marine accidents. Wei et al. [49] combined HFACS with expert subjective assessment methods and Grey System Theory to analyze human error in aviation accidents. Chiu et al. [10] used a fuzzy TOPSIS in combination with HFACS to assess air transportation maintenance tasks. Akyuz [2] used the analytic network process (ANP) combined with the HFACS to explore serious gas leakage incidents by liquefied petroleum gas carriers. Hsieh et al. [18] combined AHP and TOPSIS with HFACS to evaluate human error in Intensive Care Units (ICUs) in Taiwan. Havle and Kılıç [16] applied a combination of triangular fuzzy numbers and AHP with HFACS to analyze air traffic navigation errors in the North Atlantic. Chen et al. [9] combined interval type-2 fuzzy numbers and Prospect Theory with HFACS to explore the human factors leading to vessel accidents.

In addition, there have been many studies focusing on verifying the reliability of HFACS [11, 13, 28, 35, 36] 
proving that HFACS can be used to analyze human factors in a system or organization. Zhang et al. [55] and Zhang et al. [56] used HFACS to investigate the factors influencing major road traffic accidents in China. They summarized the human factors into the five categories of "unsafe behavior," "preconditions for unsafe behaviors," "unsafe supervision," "organizational influence," and "external factors." Past studies have shown that the consideration of external factors can make the HFACS model broader in scope. It can be applied for comprehensively and systematically identifying the factors of active failure and latent failure in an organization. It can further help the user to understand potential causes and correlations that have led to the accident. However, the HFACS model does not take into account that information may be difficult to quantify or that part of the information may be missing, and lacks the ability to assess the $S, O$, and $D$ of the real problem.

\section{FMEA combined with MCDM}

The FMEA model was developed by the Grumman Aircraft Corporation in the 1960s to analyze the flight control systems of naval aircraft [14]. It is a proactive risk assessment technology [7]. Over the past 50 years, it has been used in various fields, especially for the evaluation of the failure modes of products or systems. Failure is unavoidable in most systems. It is important to eliminate possible failures and prevent system-related problems in advance. The FMEA assessment is based on three risk factors, the $S, O$, and $D$, which together comprise the RPN $=S \times O \times D$, which is quantified based on the opinions of experts expressed through linguistic variables or through estimated values and critical analysis of the failure modes [25]. However, the RPN has often been criticized as having the following shortcomings [31]:

1. The FMEA assumes that these three factors have same importance weights.

2. Different $S, O$, and $D$ ratings may produce the same RPN value.

3. The RPN calculation is too simplistic and problems exist because the multiplication process makes the results sensitive to any small change in the evaluation of the risk factors.

4. Only three factors are considered while other important factors, such as cost, correction time, etc. are ignored.

Many methods have been proposed to improve the traditional FMEA by overcoming the shortcomings mentioned above. For example, Liu et al. [24] reviewed 169 papers related to the application of MCDM method published between 1979 and 2018 in efforts to solve the shortcomings and improve the evaluation efficiency of the traditional FMEA. In the real world, evaluation teams are often com- posed of experts with different areas of expertise and from different departments. Uncertainties in their assessment can arise due to time pressure, insufficient information, differences in linguistic scores and differences of opinion between the experts, or simply because of the vagaries of the risk assessment process itself, as well as inaccuracy, uncertainty and hesitation. Uncertainty theory methods have been applied to overcome these problems. The most common approach has been to use fuzzy set theory to deal with the uncertainty issue, followed by evidence theory, intuitionistic fuzzy set theory, 2-tuples fuzzy language theory, etc. In recent years, FMEA has been applied in combination with novel fuzzy theories and linguistic variable methods. For example, Jiang et al. [19] combined FMEA with Znumbers for the evaluation of aircraft turbine runner blades; Mohsen and Fereshteh [33] merged FMEA with $Z$-numbers to study the failure modes of geothermal power plant systems; Lo and Liou [30] combined FMEA with grey theory to explore potential failure modes of smartphones. Clearly, the problems of ambiguity, inaccuracy, and uncertainty in decision-making and judgment of risk assessment can be more effectively dealt with using uncertainty theory. However, to date, no study has used combined $Z$-numbers with the BWM method to increase the accuracy of this method for calculating the importance of the risk factors.

\section{Research gap}

A review of the literature review shows little effort to integrate HFACS and FMEA to form a comprehensive risk assessment framework for traffic safety and transportation management. Therefore, in this study, we first use HFACS to explore the potential failure modes of intercity bus traffic accidents. Then, FMEA is applied to evaluate the risk factors and obtain the risk evaluation matrix. Finally, Z-BWM is used to determine the weights of the risk factors, and Z-WASPAS is used to calculate degree of risk of the failure modes. In the real world, experts are prone to "fuzzy, uncertain, and inaccurate" risk assessments. Therefore, $Z$-numbers are applied to represent the reliability of this fuzzy information. The evaluation of road traffic risk through $Z$-BWM combined with $Z$-WASPAS allows us to obtain more reliable results.

\section{The proposed hybrid model}

\section{HFACS}

The HFACS is a classification method for the exploration of human error mainly for the analysis of accidents caused by human behavior. It was first used by the US Air Force to investigate and analyze the human factors leading to aviation accidents. This method was developed by Shappell and Wieg- 
mann [45] within the framework of human accident causality based on the so-called Swiss cheese model of human error originally proposed by Reason [40].

As in the Swiss cheese model, there are four layers in the HFACS framework. Each layer represents a different level of protection in the system, with the upper level affecting the next levels. The aim in risk management, is to try to reduce the errors that occur at all levels in the system, in order to reduce the occurrence of accidents. This framework has been widely applied in different fields, for rail transport, shipping, medical care and biochemistry, but especially in transportation systems, attracting the time and energies of a large number of researchers. However, it has been found that there are still shortcomings to human error identification methods. To improve the shortcomings of the traditional HFACS model for accident analysis, it is combined other methods. For example, the Fuzzy AHP has been combined with the HFACS framework to identify the key factors of human error in the control room of a nuclear power plant [21]. The AHP and fuzzy TOPSIS were combined with the HFACS method, to identify and prioritize failure modes based on the analysis of 157 adverse medical events [17]. Sarıalioğlu et al. [44] used fuzzy fault tree analysis (FTA) combined with an HFACS model to analyze vessel engine room fires and explosion accidents. The afore-mentioned studies have proven that the systematic and complete model architecture of HFACS can effectively and reasonably analyze the human factors that cause system problems.

\section{FMEA}

FMEA is widely used in product design, production processes, and for quality assurance or system operation safety and reliability requirements. This method requires the formation of an expert team from different professional fields for identification of failure modes based on the collected opinions of the team members. The failure modes are then sorted according to their risk level. This is a proactive assessment technology for the elimination of potential risks [7]. The evaluation and selection of key factors is the first step in risk assessment using FMEA. In the traditional model, the experts use linguistic scoring methods to assess the severity of the three risk factors of severity, occurrence, and detection. The scores are then simply multiplied to obtain the risk priority number for analyzing the failure mode [25].

In this study, it is assumed that any accidents in an intercity bus system will cause significant casualties and financial losses, so a fourth risk factor, $E$, is added. Table 1 shows the four risk factors of the risk assessment scale. The corresponding linguistic variables are given in the table, and responses range in value from 1 to 10 . The higher the value of each risk factor, the higher the risk of the failure mode. Severity refers to the magnitude of the "impact" of system failure. If the problem is serious, a higher severity value will be assigned. Occurrence rate refers to the frequency with which failure modes may occur and is described qualitatively. Detection refers to the possibility of detecting and discovering the failure before it occurs [4]. The expected cost refers to the cost for the implementation of risk prevention measures. If the costs of the occurrence of failure and action for improvement are underestimated or ignored, it may lead to greater losses. The final risk priority index is used to assess the severity of risks and failures, and to judge the priority for improvement.

The original RPN index ignores the relative importance of the risk factors in the key analysis. Hence, various weighting methods have been used to determine the weights of the risk factors [24]. The shortcomings of the traditional FMEA risk assessment method can be overcome by combining it with the MCDM method. The BWM is chosen as the weighting method in this study because of its ease-of-operation for the decision maker. Also, fewer pairwise comparisons are needed than for the popular AHP method. In addition, considering the ambiguity, inaccuracy, and uncertainty of the expert judgments, this study uses $Z$-numbers to integrate this vague and uncertain information.

\section{Z-BWM}

The Z-numbers, originally proposed by Zadeh [52] as a soft calculation method for dealing with incomplete or uncertain information. The $Z$-number contains two kinds of fuzzy information, the evaluation value, and the evaluation confidence. The degree of certainty of a fuzzy event can be measured by the "probability" and the "confidence." With the application of $Z$-numbers these two types of information are converted into a set of fuzzy numbers. The $Z$-BWM results clearly reflect the degree of confidence in the expert judgements, so as to obtain more realistic appraisal results from the experts. For a more detailed descriptions of the original BWM method see Rezaei [42].

The scale used for pairwise comparison of the importance between risk factors is as follows: "Equally Important (EI) (1, 1, 1)," "Weakly Important (WI) (2, 3, 4)," "Fairly Important (FI) $(4,5,6)$," "Very Important (VI) (6, 7, 8)," "Absolutely Important (AI) $(8,9,9)$." The five-point scale adopted for confidence assessment of expert judgments includes "Very Low (VL) $(0,0,0.3)$," "Low (L) $(0.1,0.3,0.5)$," "Medium (M) $(0.3,0.5,0.7)$," "High $(\mathrm{H})(0.5,0.7,0.9)$, ," "Very High (VH) $(0.7,1,1)$." The linguistic variables and corresponding membership functions for Z-BWM are shown in Table 2. For example, when the decision maker evaluates the importance of factor $S$ in comparison to factor $O$, it is given as "FI," and the degree of confidence in the evaluation scale is " $H$ ". The corresponding membership function is thus $(3.35,4.18$, 5.02).

The steps of $Z$-BWM are summarized as follows: 
Table 1 The four risk factors on the risk assessment scale

\begin{tabular}{lllll}
\hline Level & Severity & Occurrence & Detectability & Expected cost \\
\hline 1 & No & Almost never & Almost certain & Almost no cost \\
2 & Very slight & Remote & Very high & Very low \\
3 & Slight & Very slight & High & Low \\
4 & Minor & Slight & Moderately high & Slight \\
5 & Moderate & Low & Medium & Moderate \\
6 & Significant & Medium & Low & Moderately high \\
7 & Major & Moderately high & Slight & High \\
8 & Extreme & High & Slight & Very high \\
9 & Serious & Very high & Remote & Extremely high \\
10 & Hazardous & Almost certain & Almost impossible & Almost the same cost \\
\hline
\end{tabular}

Table 2 The linguistic variables for $Z$-BWM and their membership functions

\begin{tabular}{llllll}
\hline Importance & Confidence & \multicolumn{3}{c}{} \\
\cline { 2 - 5 } & $\mathrm{VL}$ & $\mathrm{L}$ & $\mathrm{M}$ & $\mathrm{H}$ & $\mathrm{VH}$ \\
\hline $\mathrm{EI}$ & $(1,1,1)$ & $(1,1,1)$ & $(1,1,1)$ & $(1,1,1)$ & $(1,1,1)$ \\
$\mathrm{WI}$ & $(0.63,0.95$, & $(1.10,1.64$, & $(1.41,2.12$, & $(1.67,2.51$, & $(1.90,2.85$, \\
& $1.26)$ & $2.19)$ & $2.83)$ & $3.35)$ & $3.79)$ \\
FI & $(1.26,1.58$, & $(2.19,2.74$, & $(2.83,3.53$, & $(3.35,4.18$, & $(3.79,4.74$, \\
& $1.90)$ & $3.29)$ & $4.24)$ & $5.02)$ & $5.69)$ \\
VI & $(1.90,2.21$, & $(3.29,3.84$, & $(4.24,4.95$, & $(5.02,5.86$, & $(5.69,6.64$, \\
& $2.53)$ & $4.38)$ & $5.66)$ & $6.69)$ & $7.59)$ \\
AI & $(2.53,2.85$, & $(4.38,4.93$, & $(5.66,6.36$, & $(6.69,7.53$, & $(7.59,8.54$, \\
& $2.85)$ & $4.93)$ & $6.36)$ & $7.53)$ & $8.54)$ \\
\hline
\end{tabular}

Step 1. Decide on the most and least important risk factors

From the risk factors defined by the FMEA method, select the most important (i.e., most satisfactory, best, or most preferred) and the least important (i.e., most unsatisfactory, worst, or least preferred).

Step 2. Compare the most important factor with the other factors to produce the $\mathrm{Z}-\mathrm{BO}$ vector

The relative importance of the most important risk factor and other risk factors is assessed by the experts using the evaluation scale, as shown in Table 2. The linguistic variable assessments range from " $\langle\mathrm{EI}, \mathrm{VL}\rangle,(1,1,1)$ " to " $\langle\mathrm{AI}, \mathrm{VH}\rangle$, $(3.33,3.80,4.28)$." Each evaluation item is given a set of $Z$-numbers. The $Z$-BO vector can be generated by

$\otimes A_{B j}=\left(\otimes a_{B 1}, \otimes a_{B 2}, \ldots, \otimes a_{B n}\right)$,

where " $\otimes$ " is represented as a $Z$-number and $\otimes a_{B j}$ represents the importance of the most important risk factor $B$ relative to risk factor $j$. The comparison between the most important risk factor and itself must be "EI" and "VH" (i.e., $\left.\otimes a_{B B}=(1,1,1)\right)$.

Step 3. Compare the remaining factors with the least important factor to produce the Z-OW vector

Similar to Step 2, the relative importance of the other risk factors is assessed by the experts by comparison with the least important risk factor, to generate the $Z$-OW vector, as follows:

$\otimes A_{j W}=\left(\otimes a_{1 W}, \otimes a_{2 W}, \ldots, \otimes a_{n W}\right)^{T}$,

where $\otimes a_{j W}$ represents the importance of the remaining risk factor $j$ relative to the least important risk factor $W$, and $\otimes a_{W W}=(1,1,1)$.

Step 4. Calculate the optimal weight value of each risk factor $\left(\otimes w_{1}^{*}, \otimes w_{2}^{*}, \ldots, \otimes w_{n}^{*}\right)$..

The two vectors of $Z$-BWM ( $Z$-BO and $Z$-OW vectors) can be converted into a nonlinear constrained optimization problem. Please refer to Aboutorab et al. [1] for details about the conversion process and principles. The nonlinear mathematical equations generated by $Z$-BWM are

$\operatorname{Min} \otimes \zeta$.

$$
\text { s.t. }\left\{\begin{array}{c}
\left|\otimes w_{B}-\otimes a_{B j} \cdot \otimes w_{j}\right| \leq \otimes \zeta \\
\left|\otimes w_{j}-\otimes a_{j W} \cdot \otimes w_{W}\right| \leq \otimes \zeta \\
\sum_{j=1}^{n} R\left(\otimes w_{j}\right)=1 \\
l_{j}^{w} \leq m_{j}^{w} \leq u_{j}^{w} \\
l_{j}^{w} \geq 0 \\
j=1,2, \ldots, n
\end{array}\right. \text {. }
$$


where $\otimes \zeta=\left(l^{\zeta}, m^{\zeta}, u^{\zeta}\right), \otimes w_{j}=\left(l_{j}^{w}, m_{j}^{w}, u_{j}^{w}\right), \otimes a_{B j}=$ $\left(l_{B j}, m_{B j}, u_{B j}\right)$, and $\otimes a_{j W}=\left(l_{j W}, m_{j W}, u_{j W}\right)$. Considering $l^{\zeta} \leq m^{\zeta} \leq u^{\zeta}$, we assume $\otimes \zeta^{*}=\left(k^{*}, k^{*}, k^{*}\right), k^{*} \leq l^{\zeta}$. Equation (3) can be converted to Eq. (4):

$\operatorname{Min} \otimes \zeta^{*}$.

$$
\text { s.t. }\left\{\begin{array}{c}
\left|\left(l_{B}^{w}, m_{B}^{w}, u_{B}^{w}\right)-\left(l_{B j}, m_{B j}, u_{B j}\right) \cdot\left(l_{j}^{w}, m_{j}^{w}, u_{j}^{w}\right)\right| \leq\left(k^{*}, k^{*}, k^{*}\right) \\
\left|\left(l_{j}^{w}, m_{j}^{w}, u_{j}^{w}\right)-\left(l_{j W}, m_{j W}, u_{j W}\right) \cdot\left(l_{W}^{w}, m_{W}^{w}, u_{W}^{w}\right)\right| \leq\left(k^{*}, k^{*}, k^{*}\right) \\
\sum_{j=1}^{n} R\left(\frac{l_{j}^{w}+4 \cdot m_{j}^{w}+u_{j}^{w}}{6}\right)=1 \\
l_{j}^{w} \leq m_{j}^{w} \leq u_{j}^{w} \\
l_{j}^{w} \geq 0 \\
j=1,2, \ldots, n
\end{array}\right.
$$

The optimal fuzzy weights $\left(\otimes w_{1}^{*}, \otimes w_{2}^{*}, \ldots, \otimes w_{n}^{*}\right)$ can be obtained by solving Eq. (4).

Step 5. Integrate the Z-BWM analysis results from the experts

This study uses the arithmetic mean to integrate the $Z$ BWM results from the experts, that is, the obtained multiple sets of weights are averaged to generate the criterion group weights $\otimes w_{j}^{a g g}$.

\section{Z-WASPAS}

In the original FMEA method, the risk priority number is obtained simply by multiplying the three risk factors together. However, different combinations might generate the same RPN number and they are strongly sensitive to variations in the RPN element evaluations [31]. To remedy the above shortcomings, WASPAS, a hybrid MCDM method, was developed by combining two systems the weighted sum model (WSM) and weighted product model (WPM). This method has been used to deal with various MCDM problems. Its ranking accuracy is higher than the traditional methods [3, 5]. The $Z$-WASPAS method proposed in this paper is used to determine the risk scores of the failure modes and their ranking. The Z-WASPAS operation steps are as follows:

Step 1. Obtain the initial assessment matrix

The linguistic variables in Table 1 are applied to identify the scores of the failure modes. Next, the experts assign confidence levels for each score according to the five-level scale: "Very Low (VL) $(0,0,0.3)$," "Low (L) $(0.1,0.3,0.5)$," "Medium (M) $(0.3,0.5,0.7)$," "High $(\mathrm{H})(0.5,0.7,0.9)$," or "Very High $(\mathrm{VH})(0.7,1,1)$." The linguistic variables for $Z$ WASPAS and its corresponding membership functions are listed in Table 3.

Assume that the FMEA team has $k$ experts. These experts assess the score of failure mode $i$ for risk factor $j$ to obtain the initial $\boldsymbol{D}$ assessment matrix (Eq. 5), where $k=1,2, \ldots$, $p ; j=1,2, \ldots, n$; and $i=1,2, \ldots, m$.

$$
\otimes D^{(k)}=\left[\begin{array}{cccc}
\otimes d_{11}^{(k)} & \otimes d_{12}^{(k)} & \cdots & \otimes d_{1 n}^{(k)} \\
\otimes d_{21}^{(k)} & \otimes d_{22}^{(k)} & \cdots & \otimes d_{2 n}^{(k)} \\
\vdots & \vdots & \ddots & \vdots \\
\otimes d_{m 1}^{(k)} & \otimes d_{m 2}^{(k)} & \cdots & \otimes d_{m n}^{(k)}
\end{array}\right],
$$

where $\otimes d_{i j}^{(k)}$ represents the score of the $k$ th expert's assessment of failure mode $i$ under risk factor $j$, and $\otimes d_{i j}^{(k)}=$ $\left(\otimes d_{i j}^{(k), l}, \otimes d_{i j}^{(k), m}, \otimes d_{i j}^{(k), u}\right)$.

Step 2. Use Eq. (6)to calculate the average assessment matrix

$\otimes X=\left[\begin{array}{cccc}\otimes x_{11} & \otimes x_{12} & \cdots & \otimes x_{1 n} \\ \otimes x_{21} & \otimes x_{22} & \cdots & \otimes x_{2 n} \\ \vdots & \vdots & \ddots & \vdots \\ \otimes x_{m 1} & \otimes x_{m 2} & \cdots & \otimes x_{m n}\end{array}\right]$,

where $\otimes x_{i j}=\frac{\sum_{k=1}^{p} \otimes d_{i j}}{k}$ and $\otimes x_{i j}^{(k)}=$ $\left(\otimes x_{i j}^{(k), l}, \otimes x_{i j}^{(k), m}, \otimes x_{i j}^{(k), u}\right)$.

Step 3. Calculate the normalized matrix

To unify the units and score range of the assessment risk factors, the normalized matrix Eq. (7) is obtained through Eq. (8) as follows:

$\otimes P=\left[\otimes p_{i j}\right]_{m \times n}$,

$\otimes p_{i j}=\frac{\otimes a_{i j}}{10}$.

Step 4. Calculate the performance indexes WSM and WSP

In this step, the group weights obtained for Z-BWM are used as the parameter values for the calculation of performance indexes WSM and WSP.

$\otimes S Q_{i}=\sum_{j=1}^{n} \otimes p_{i j} . \otimes w_{j}^{a g g}$,

$\otimes P Q_{i}=\prod_{j=1}^{n}\left(\otimes p_{i j}\right)^{\otimes w_{j}}$.

Step 5. Calculate the integrated risk index $\varphi$.

The centroid method is used to deburr the fuzzy value, for example, $\otimes \theta=\left(\theta^{l}, \theta^{m}, \theta^{u}\right)$, to obtain the crisp value $(\theta)$, as shown in Eq. (11).

$\theta=\frac{\theta^{l}+4 \cdot \theta^{m}+\theta^{u}}{6}$ 
Table 3 The linguistic variables for $Z$-WASPAS and their membership functions

\begin{tabular}{|c|c|c|c|c|c|}
\hline \multirow{2}{*}{$\begin{array}{l}\mathrm{S}, \mathrm{O}, \mathrm{D}, \\
\text { and } \mathrm{E} \\
\text { Level }\end{array}$} & \multicolumn{5}{|l|}{ Confidence } \\
\hline & $\mathrm{VL}$ & $\mathrm{L}$ & $\mathrm{M}$ & $\mathrm{H}$ & $\mathrm{VH}$ \\
\hline 1 & $(0.32,0.32,0.47)$ & $(0.55,0.55,0.82)$ & $(0.71,0.71,1.06)$ & $(0.84,0.84,1.25)$ & $\begin{array}{c}(0.95,0.95 \\
1.42)\end{array}$ \\
\hline 2 & $(0.47,0.63,0.79)$ & $(0.82,1.10,1.37)$ & $(1.06,1.41,1.77)$ & $(1.25,1.67,2.09)$ & $\begin{array}{c}(1.42,1.90 \\
2.37)\end{array}$ \\
\hline 3 & $(0.79,0.95,1.11)$ & $(1.37,1.64,1.92)$ & $(1.77,2.12,2.47)$ & $(2.09,2.51,2.93)$ & $\begin{array}{c}(2.37,2.85 \\
3.32)\end{array}$ \\
\hline 4 & $(1.11,1.26,1.42)$ & $(1.92,2.19,2.47)$ & $(2.47,2.83,3.18)$ & $(2.93,3.35,3.76)$ & $\begin{array}{c}(3.32,3.79 \\
4.27)\end{array}$ \\
\hline 5 & $(1.42,1.58,1.74)$ & $(2.47,2.74,3.01)$ & $(3.18,3.53,3.89)$ & $(3.76,4.18,4.60)$ & $\begin{array}{c}(4.27,4.74 \\
5.22)\end{array}$ \\
\hline 6 & $(1.74,1.90,2.06)$ & $(3.01,3.29,3.56)$ & $(3.89,4.24,4.60)$ & $(4.60,5.02,5.44)$ & $\begin{array}{c}(5.22,5.69 \\
6.17)\end{array}$ \\
\hline 7 & $(2.06,2.21,2.37)$ & $(3.56,3.84,4.11)$ & $(4.60,4.95,5.30)$ & $(5.44,5.86,6.27)$ & $\begin{array}{c}(6.17,6.64 \\
7.12)\end{array}$ \\
\hline 8 & $(2.37,2.53,2.69)$ & $(4.11,4.38,4.66)$ & $(5.30,5.66,6.01)$ & $(6.27,6.69,7.11)$ & $\begin{array}{c}(7.12,7.59 \\
8.06)\end{array}$ \\
\hline 9 & $(2.69,2.85,3.00)$ & $(4.66,4.93,5.21)$ & $(6.01,6.36,6.72)$ & $(7.11,7.53,7.95)$ & $\begin{array}{c}(8.06,8.54 \\
9.01)\end{array}$ \\
\hline 10 & $(3.00,3.16,3.16)$ & $(5.21,5.48,5.48)$ & $(6.72,7.07,7.07)$ & $(7.95,8.37,8.37)$ & $\begin{array}{c}(9.01,9.49 \\
9.49)\end{array}$ \\
\hline
\end{tabular}

The next step is to de-fuzzify all fuzzy numbers using Eq. (11). Both WSM and WSP are considered in Z-WASPAS, and the preference ratio of these two is determined by the parameter. The integrated risk index $\varphi$ is

$\varphi_{i}=\lambda s Q_{i}+(1-\lambda) p Q_{i}$

The failure modes are ranked according to the index $\varphi$. The failure mode with the highest performance value $\varphi$ has the highest priority for improvement.

\section{Illustration in a real case study}

This study uses data for inter-city buses in Taiwan for empirical analysis. Many highway bus accidents, often causing a large number of casualties, have occurred in recent years. For example, in September 2017, an inter-city highway bus dodging another vehicle lost control and crashed into a guardrail, resulting in 6 deaths and 11 injuries. Another highway bus roll-over accident which occurred in June 2019 caused 3 deaths and 13 injuries. In addition to the injuries and deaths, serious traffic accidents also pose a huge challenge to the economy. The annual economic losses caused by traffic accidents accounted for about $3.13 \%$ of Taiwan's GDP [54]. All of this makes effective reduction of possible accidents before they occur an urgent issue for government.

\section{Identifying the failure modes through HFACS}

The literature review in "Literature review" shows that although the HFACS has been used for comprehensive risk assessment in various fields, most of these studies did not consider the impact of external factors. This study thus adds "external factors" to the HFACS analysis. Initially, 5 types of human factors and 15 failure modes were derived from the literature review. Then, 10 experts were invited as an assessment team. The team members included supervisors from government agencies, senior researchers from a transportation institute, mangers of inter-city bus companies, and accident investigators. The experts have an average of more than 10 years' experience in related fields with rich levels of professionalism, knowledge, and industry-related practical experience, thus, their assessment results are deemed credible.

The five human factors include "external factors," "organizational influence," "unsafe supervision," "preconditions for unsafe behavior," and "unsafe behavior." Based on the HFACS analysis and two rounds of interviews, some of the initial failure modes were modified and five more added to more accurately reflect the operating environment in Taiwan. Two failure modes from external factors and 18 failure modes from internal factors comprise the evaluation framework in this case study. The two failure modes for external factors are "Regulatory omissions 
Fig. 1 Proposed HFACS framework for analysis of potential failure modes for inter-city buses

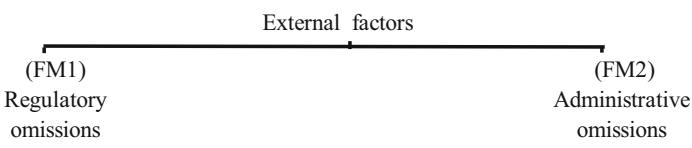

\begin{tabular}{ccccc}
\multicolumn{5}{c}{ Organizational influence } \\
(FM3) & (FM4) & (FM5) & (FM6) & (FM7) \\
Human & Financial & Equipment & Safety & Organizational \\
resources & resources & and resources & atmosphere & operation
\end{tabular}

\begin{tabular}{cccc}
\multicolumn{4}{c}{ Unsafe supervision } \\
(FM8) & (FM9) & (FM10) & (FM11) \\
Insufficient & Incompletely & Failure to & Regulatory \\
supervision & planned & correct & violations \\
& operating & known errors & \\
& mechanism & &
\end{tabular}

Preconditions for unsafe behavior

$\begin{array}{ccccc}\text { (FM12) } & \text { (FM13) } & \text { (FM14) } & (\text { FM15) } & (\text { FM16) } \\ \text { Personal } & \text { Human } & \text { Poor Mental } & \text { Poor Physical } & \text { Physical/ } \\ \text { readiness } & \text { Resource } & \text { State } & \text { State } & \text { Psychological } \\ & \text { Management } & & & \text { Limitations }\end{array}$

\begin{tabular}{cccc}
\multicolumn{3}{c}{ Unsafe behavior } \\
(FM17) & (FM18) & (FM19) & (FM20) \\
Driver & Driver & Driver & Driver \\
decision- & operating & perception & violation of \\
making error & error & error & traffic \\
& & & regulation
\end{tabular}

(FM1)" and "Administrative omissions (FM2)". The 18 failure modes within internal organizations include "Human resources (FM3)," "Financial resources (FM4)," "Equipment and resources (FM5)," "Safety atmosphere (FM6)," "Organizational operation (FM7)," "Insufficient supervision (FM8)," "Incompletely planned operating mechanism (FM9)," "Failure to correct known errors (FM10)," "Regulatory violations (FM11)," "Personal readiness (FM12)," "Human resource management (CRM) (FM13)," "Poor mental state (FM14)," "Poor physical state (FM15)," "Physical/Psychological limitations (Intelligence) (FM16)," "Driver decision-making error (FM17)," "Driver operating error (FM18)," "Driver perception error (FM19)," and "Driver violations (FM20)."

The five types of human factors and the final 20 failure modes identified by the HFACS method are listed in Fig. 1 and described in detail in Table 4.

The HFACS framework is a useful tool to assist in the investigation and establishment of preventive measures for traffic accidents. The expert team can effectively and systematically distinguish potential failure modes that cause accidents within the organization. However, the failure modes obtained by the HFACS model cannot quantify their degree of risk and lacks a tool for the assessment of the severity, frequency, and measurability of actual problems.

To remedy the shortcomings of the original FMEA method, the modified model considers factor importance and the RPN value calculated by the WASPAS method. In addition, $Z$-numbers are incorporated to consider the ambiguity and uncertainty of the experts' survey responses. The proposed model uses $Z$-numbers combined with BWM to determine the importance of the risk factors, and the WASPAS method to prioritize the failure modes.

\section{Weighted RPN elements through Z-BWM}

The advantages of the Z-BWM and its calculation process are explained in detail in "Z-BWM". First, each expert is required to select the most important and least important risk factors. The steps to obtain the $Z$-BO and $Z$-OW vectors from each expert are based on the evaluation scale in Table 2 . The results obtained from professional feedback from the 10 experts are shown in Tables 5 and 6 . For example, as indicated in Table 5, the first expert believes that $S$ is the most important risk factor. Therefore, compared with other risk factors, the $Z$-BO vector formed by $S$ is $\{(1,1,1),(3.35,4.18$, 5.02), (7.59, 8.54, 8.54), (4.24, 4.95, 5.66) $\}$. Similarly, $D$ is selected as the least important risk factor, and the transposed $Z$-OW vector is $\{(7.59,8.54,8.54),(5.02,5.86,6.69),(1$, $1,1),(4.24,4.95,5.66)\}$, as shown in Table 6 . All experts' responses are processed similarly. Before performing the $Z$ BWM calculation, the consistency ratio (CR) is calculated for all BWM questionnaire responses to confirm the logic and reliability of the experts' answers. The average CR value is 0.035 , indicating a high degree of consistency [42]. 
Table 4 Proposed failure mode evaluation

Level Code

External factors

FM1

Failure mode

Regulatory omissions

FM2

Administrative omissions

Organizational influence

Human resources

FM4 Financial resources

FM5 Equipment and resources

FM6 Safety atmosphere

FM7 Organizational operation

Unsafe supervision

FM8 Insufficient supervision

FM9 Insufficient supervision

FM10

Failure to correct known errors
Description

1. Laws and regulations are not rigorous or precise enough

2. Regulations are out-of-date and need amendment to meet industry and social circumstance demands

1. The government department has not implemented the relevant laws and regulations or carried out its supervisory and management responsibilities

2. Failure to strengthen policy advocacy or insufficient safety subsidy policies

1. Drivers demonstrate unsuitable personality traits, such as hostility, emotional, nervous, aggressive etc

2. The shortage of drivers in the work force affects the quality and safety of transportation services

1. Insufficient budgeting for regular vehicle renewal and equipment maintenance

2. Inappropriate salary and bonus system

1. Lack of regular vehicle inspection and maintenance

2. Using inappropriate vehicle or maintenance equipment

1. Safety-related issues are not frequently or actively discussed

2. Lack of mutual encouragement to drive safely

1. No regular review of safety plans and procedure

2. No rigorous working hour rules or violation record system

1. Failure to conduct regular safety inspections of drivers and vehicles

2. Failure to conduct on-the-job training for drivers and strengthen driving safety education and training

1. Inappropriate management resulting in non-compliance or improper working hours

2. Lack of standardization of working procedures and risk assessment mechanisms

1. Failure of the company's administrative division to issue warnings and initiate improvement measures for known defects in the system

2. Failure to correct improper driving habits 
Table 4 continued

\begin{tabular}{|c|c|c|c|}
\hline Level & Code & Failure mode & Description \\
\hline & FM11 & Regulatory violations & $\begin{array}{l}\text { Managers ignore safety regulations and } \\
\text { fail to follow procedures in the execution } \\
\text { of daily operating tasks }\end{array}$ \\
\hline \multirow[t]{5}{*}{ Pre-conditions for unsafe behavior } & FM12 & Personal readiness & $\begin{array}{l}\text { 1. Drivers have insufficient rest between } \\
\text { shifts } \\
\text { 2. Drivers are not familiar with road } \\
\text { conditions } \\
\text { 3. Driver's personal health is poor }\end{array}$ \\
\hline & FM13 & Human resource management CRM & $\begin{array}{l}\text { 1. Poor communication between } \\
\text { management staff and drivers } \\
\text { 2. Interpersonal relationships in the work } \\
\text { team are not harmonious }\end{array}$ \\
\hline & FM14 & Poor mental state & $\begin{array}{l}\text { 1. Attitude or personality problems, such } \\
\text { as carelessness or impatience } \\
\text { 2. Fatigue causing inattention }\end{array}$ \\
\hline & FM15 & Poor physical state & $\begin{array}{l}\text { Loss of driving control due to illness, } \\
\text { medications, physical discomfort or } \\
\text { dizziness }\end{array}$ \\
\hline & FM16 & $\begin{array}{l}\text { Physical/psychological limitations } \\
\text { (intelligence) }\end{array}$ & $\begin{array}{l}\text { 1. Work load exceeds the level that the } \\
\text { driver can bear physically/mentally } \\
\text { 2. Deterioration of vision or physical } \\
\text { response }\end{array}$ \\
\hline \multirow[t]{4}{*}{ Unsafe behavior } & FM17 & Driver decision-making error & $\begin{array}{l}\text { 1. Misjudging the driving status of other } \\
\text { vehicles and responding to emergencies } \\
\text { 2. Misjudgment of road conditions }\end{array}$ \\
\hline & FM18 & Driver operating error & $\begin{array}{l}\text { 1. Improper driving behavior, such as } \\
\text { incorrect lane changing, deviating from } \\
\text { lanes, failure to maintain safe driving } \\
\text { distance, etc } \\
\text { 2. Failure to check vehicle condition } \\
\text { before departure }\end{array}$ \\
\hline & FM19 & Driver perception error & $\begin{array}{l}\text { 1. Monotonous road conditions lead to } \\
\text { perception errors } \\
\text { 2. Poor vision at night }\end{array}$ \\
\hline & FM20 & Driver violations & $\begin{array}{l}\text { 1. Violation of road traffic regulations or } \\
\text { drunk driving } \\
\text { 2. Distracted driving, for example, using a } \\
\text { mobile phone or tablet device while } \\
\text { driving }\end{array}$ \\
\hline
\end{tabular}

Table $5 \mathrm{Z}$-BO vectors

\begin{tabular}{llllll}
\hline Expert no & Best & $S$ & $O$ & $D$ & $E$ \\
\hline 1 & $S$ & $(1,1,1)$ & $(3.35,4.18,5.02)$ & $(7.59,8.54,8.54)$ & $(4.24,4.95,5.66)$ \\
2 & $S$ & $(1,1,1)$ & $(5.02,5.86,6.69)$ & $(3.79,4.74,5.69)$ & $(2.83,3.53,4.24)$ \\
3 & $D$ & $(6.69,7.53,7.53)$ & $(3.79,4.74,5.69)$ & $(1,1,1)$ & $(1.67,2.51,3.35)$ \\
4 & $D$ & $(1.90,2.21,2.53)$ & $(5.02,5.86,6.69)$ & $(1,1,1)$ & $(2.83,3.53,4.24)$ \\
5 & $S$ & $(1,1,1)$ & $(1.41,2.12,2.83)$ & $(1.67,2.51,3.35)$ & $(5.69,6.64,7.59)$ \\
6 & $E$ & $(3.35,4.18,5.02)$ & $(1.90,2.85,3.79)$ & $(1.41,2.12,2.83)$ & $(1,1,1)$ \\
7 & $S$ & $(1,1,1)$ & $(1.67,2.51,3.35)$ & $(5.69,6.64,7.59)$ & $(3.35,4.18,5.02)$ \\
8 & $S$ & $(1,1,1)$ & $(1.67,2.51,3.35)$ & $(3.35,4.18,5.02)$ & $(3.79,4.74,5.69)$ \\
9 & $S$ & $(1,1,1)$ & $(3.35,4.18,5.02)$ & $(1.67,2.51,3.35)$ & $(3.79,4.74,5.69)$ \\
10 & $S$ & $(1,1,1)$ & $(1.67,2.51,3.35)$ & $(1.67,2.51,3.35)$ & $(3.79,4.74,5.69)$ \\
\hline
\end{tabular}


Table 6 Z-OW vectors

\begin{tabular}{|c|c|c|c|c|c|}
\hline Expert no & 1 & 2 & 3 & 4 & 5 \\
\hline Worst & $D$ & $O$ & $S$ & $O$ & $E$ \\
\hline$S$ & $(7.59,8.54,8.54)$ & $(5.02,5.86,6.69)$ & $(1,1,1)$ & $(2.83,3.53,4.24)$ & $(5.69,6.64,7.59)$ \\
\hline$O$ & $(5.02,5.86,6.69)$ & $(1,1,1)$ & $(2.83,3.53,4.24)$ & $(1,1,1)$ & $(3.35,4.18,5.02)$ \\
\hline$D$ & $(1,1,1)$ & $(1.90,2.85,3.79)$ & $(6.69,7.53,7.53)$ & $(5.02,5.86,6.69)$ & $(3.35,4.18,5.02)$ \\
\hline$E$ & $(4.24,4.95,5.66)$ & $(1.41,2.12,2.83)$ & $(5.02,5.86,6.69)$ & $(5.02,5.86,6.69)$ & $(1,1,1)$ \\
\hline Expert no & 6 & 7 & 8 & 9 & 10 \\
\hline Worst & $S$ & $E$ & $E$ & $D$ & $E$ \\
\hline$S$ & $(1,1,1)$ & $(3.35,4.18,5.02)$ & $(3.79,4.74,5.69)$ & $(1.67,2.51,3.35)$ & $(3.79,4.74,5.69)$ \\
\hline$O$ & $(1.41,2.12,2.83)$ & $(4.24,4.95,5.66)$ & $(1.67,2.51,3.35)$ & $(1.41,2.12,2.83)$ & $(1.67,2.51,3.35)$ \\
\hline$D$ & $(1.41,2.12,2.83)$ & $(1.10,1.64,2.19)$ & $(3.35,4.18,5.02)$ & $(1,1,1)$ & $(1.67,2.51,3.35)$ \\
\hline E & $(3.35,4.18,5.02)$ & $(1,1,1)$ & $(1,1,1)$ & $(1.41,2.12,2.83)$ & $(1,1,1)$ \\
\hline
\end{tabular}

Expert 1's Z-BO factors and Z-OW factors are used as an example to demonstrate calculation process of the $Z$-BWM, the nonlinear mathematical model, as shown in Eq. (13).

$\operatorname{Min} \otimes \zeta^{*}$.

s.t. $\left\{\begin{array}{c}\left|\left(l_{S}^{w}, m_{S}^{w}, u_{S}^{w}\right)-(3.35,4.18,5.02) \cdot\left(l_{O}^{w}, m_{O}^{w}, u_{O}^{w}\right)\right| \leq\left(k^{*}, k^{*}, k^{*}\right) ; \\ \left|\left(l_{S}^{w}, m_{S}^{w}, u_{S}^{w}\right)-(7.59,8.54,8.54) \cdot\left(l_{D}^{w}, m_{D}^{w}, u_{D}^{w}\right)\right| \leq\left(k^{*}, k^{*}, k^{*}\right) ; \\ \left|\left(l_{S}^{w}, m_{S}^{w}, u_{S}^{w}\right)-(4.24,4.95,5.66) \cdot\left(l_{E}^{w}, m_{E}^{w}, u_{E}^{w}\right)\right| \leq\left(k^{*}, k^{*}, k^{*}\right) ; \\ \left|\left(l_{O}^{w}, m_{O}^{w}, u_{O}^{w}\right)-(5.02,5.86,6.69) \cdot\left(l_{D}^{w}, m_{D}^{w}, u_{D}^{w}\right)\right| \leq\left(k^{*}, k^{*}, k^{*}\right) ; \\ \left|\left(l_{E}^{w}, m_{E}^{w}, u_{E}^{w}\right)-(4.24,4.95,5.66) \cdot\left(l_{D}^{w}, m_{D}^{w}, u_{D}^{w}\right)\right| \leq\left(k^{*}, k^{*}, k^{*}\right) ; \\ \frac{l_{S}^{w}+4 \cdot m_{S}^{w}+u_{S}^{w}}{6}+\frac{l_{O}^{w}+4 \cdot m_{O}^{w}+u_{O}^{w}}{6}+\frac{l_{D}^{w}+4 \cdot m_{D}^{w}+u_{D}^{w}}{6}+\frac{l_{E}^{w}+4 \cdot m_{E}^{w}+u_{E}^{w}}{6}=1 ; \\ l_{S}^{w} \leq m_{S}^{w} \leq u_{S}^{w} ; l_{O}^{w} \leq m_{O}^{w} \leq u_{O}^{w} ; l_{D}^{w} \leq m_{D}^{w} \leq u_{D}^{w} ; l_{E}^{w} \leq m_{E}^{w} \leq u_{E}^{w} ; \\ l_{S}^{w}, l_{O}^{w}, l_{D}^{w}, l_{E}^{w} \geq 0 .\end{array}\right.$

Equation (13) is further expanded to get Eq. (14).

Min $k^{*}$.

s.t. $\left\{\begin{array}{c}\left|l_{S}^{w}-3.35 \cdot u_{O}^{w}\right| \leq k^{*} ;\left|m_{S}^{w}-4.18 \cdot m_{O}^{w}\right| \leq k^{*} ;\left|u_{S}^{w}-5.02 \cdot l_{O}^{w}\right| \leq k^{*} ; \\ \left|l_{S}^{w}-7.59 \cdot u_{D}^{w}\right| \leq k^{*} ;\left|m_{S}^{w}-8.54 \cdot m_{D}^{w}\right| \leq k^{*} ;\left|u_{S}^{w}-8.54 \cdot l_{D}^{w}\right| \leq k^{*} ; \\ \left|l_{S}^{w}-4.24 \cdot u_{E}^{w}\right| \leq k^{*} ;\left|m_{S}^{w}-4.95 \cdot m_{E}^{w}\right| \leq k^{*} ;\left|u_{S}^{w}-5.66 \cdot l_{E}^{w}\right| \leq k^{*} ; \\ \left|l_{O}^{w}-5.02 \cdot u_{D}^{w}\right| \leq k^{*} ;\left|m_{O}^{w}-5.86 \cdot m_{D}^{w}\right| \leq k^{*} ;\left|u_{O}^{w}-6.69 \cdot l_{D}^{w}\right| \leq k^{*} ; \\ \left|l_{E}^{w}-4.24 \cdot u_{D}^{w}\right| \leq k^{*} ;\left|m_{E}^{w}-4.95 \cdot m_{D}^{w}\right| \leq k^{*} ;\left|u_{E}^{w}-5.66 \cdot l_{D}^{w}\right| \leq k^{*} ; \\ \frac{l_{S}^{w}+4 \cdot m_{S}^{w}+u_{S}^{w}}{6}+\frac{l_{O}^{w}+4 \cdot m_{O}^{w}+u_{O}^{w}}{6}+\frac{l_{D}^{w}+4 \cdot m_{D}^{w}+u_{D}^{w}}{6}+\frac{l_{E}^{w}+4 \cdot m_{E}^{w}+u_{E}^{w}}{6}=1 \\ l_{S}^{w} \leq m_{S}^{w} \leq u_{S}^{w} ; l_{O}^{w} \leq m_{O}^{w} \leq u_{O}^{w} ; l_{D}^{w} \leq m_{D}^{w} \leq u_{D}^{w} ; l_{E}^{w} \leq m_{E}^{w} \leq u_{E}^{w} ; \\ l_{S}^{w}, l_{O}^{w}, l_{D}^{w}, l_{E}^{w} \geq 0 .\end{array}\right.$.

The weight value of the risk factor from Expert 1 can be obtained through the single-objective solution, which is presented as follows:
$\left(l_{S}^{w}, m_{S}^{w}, u_{S}^{w}\right)=(0.618,0.658,0.692) ;\left(l_{O}^{w}, m_{O}^{w}, u_{O}^{w}\right)=$ $(0.084,0.093,0.104) ;\left(l_{D}^{w}, m_{D}^{w}, u_{D}^{w}\right)=(0.056,0.062,0.071) ;$ $\left(l_{E}^{w}, m_{E}^{w}, u_{E}^{w}\right)=(0.170,0.188,0.205)$. 
Table 7 Weight results for Z-BWM

\begin{tabular}{lll}
\hline Risk factor & Weight & Rank \\
\hline$S$ & $(0.381,0.419,0.451)$ & 1 \\
$O$ & $(0.136,0.166,0.204)$ & 4 \\
$D$ & $(0.199,0.235,0.271)$ & 2 \\
$E$ & $(0.157,0.180,0.202)$ & 3 \\
\hline
\end{tabular}

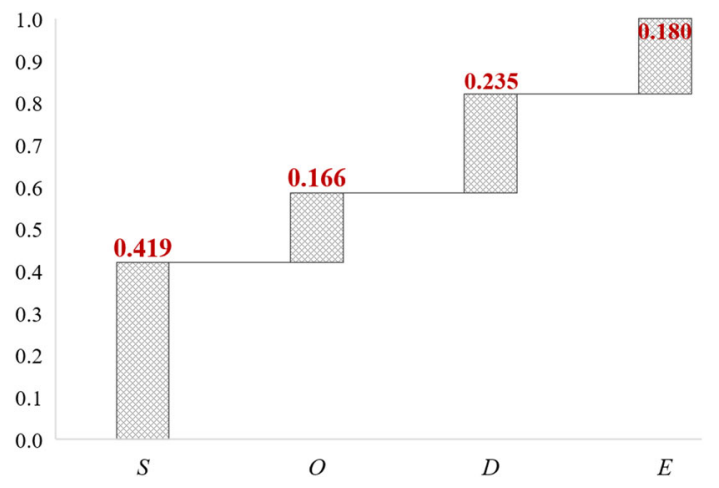

Fig. 2 Schematic diagram of the relative importance of risk factors

The group optimal weights integrated from the 10 experts' responses are listed in Table 7. Obviously, $S$ is the risk factor with the highest weight, $(0.381,0.419,0.451)$. The median value of the fuzzy $Z$-number of the risk factor is shown in the schematic diagram of the relative importance of weights in Fig. 2. Next, the $Z$-BWM results are used as one of the input parameters for the $Z$-WASPAS to find the aggregated RPN for each failure mode.

\section{Ranking failure modes through Z-WASPAS}

Inter-city bus system operations are complex and involve many internal and external organizations. Prioritizing the failure modes can allow decision makers to more effectively concentrate on certain critical failure modes. WASPAS is one of the most effective ways to solve this type of problem because its analytical process is simple and fast. It meets the needs of decision makers and supports the formulation of strategies for improvement and prevention for key failure modes. The number of failure modes does not affect the efficiency and reliability of this method. In this study, 10 experts evaluated the risk degrees of 20 potential failure modes using semantic variables as shown in Table 3. The average assessment $Z$-matrix of the 10 experts is shown in Table 8 .

The differences in importance of the risk factors are considered based on the results of the weights calculated by $Z$-BWM and are included in the Z-WASPAS calculation. Table 9 shows the $Z$-WASPAS results. The top five failure modes in the ranking are FM12, FM3, FM17, FM2, and FM18. It is determined that failure mode FM12 has the high- est integrated RPN, which is 0.5527 , therefore, it should have the highest priority for prevention and correction.

\section{Discussion}

\section{Management implications}

Using the HFACS method, the potential failure modes can be easily and systematically identified. The method considers five factors and their interaction for more effective detection of any possible failures. The modified FMEA and MCDM methods are further applied to remedy the shortcomings of the HFACS. According to the empirical results of $Z$-BWM, the priority is $S \succ D \succ E \succ O$ with the risk factor of severity having the highest $Z$-number $(0.381,0.419,0.451)$. For bus companies and government agencies, severity represents the consequences of human error as a threat to human life. This is the most important risk factor. The second place ranking is $D$. This risk factor can be divided into pre-detection and degree of discoverability when risk occurs and can be greatly reduced by regular testing and evaluation of drivers and vehicles before human error occurs. The third ranked factor is $E$, which refers to the economic cost that needs to be invested or the resources required to repair or restore functioning after failure has occurred. How to prevent or reduce the risk of high-cost human error is one of the key factors. Finally, $O$ represents the occurrence of traffic accidents due to human behavior and faulty decision-making. The occurrence rate will be reduced if the first three risk factors are properly controlled.

The $Z$-WASPAS method is used to rank the failure modes. The results of the evaluation show the following risk priority index from high to low: FM12 $\succ$ FM3 $\succ$ FM17 $\succ$ FM2 $\succ$ FM18 $\succ$ FM14 $\succ$ FM19 $\succ$ FM6 $\succ$ FM4 $\succ$ FM20 $\succ$ FM1 $\succ$ FM15 $\succ$ FM16 $\succ$ FM13 $\succ$ FM8 $\succ$ FM5 $\succ$ FM9 $\succ$ FM7 $\succ$ FM10 $\succ$ FM11. The subsequent analysis is dedicated to those failure modes ranked from number 1 to 6 , because these are the modes requiring the most urgent attention and the implementation of solutions by the management team.

The first ranked failure mode is personal readiness (FM12) with an RPN value of 0.5527 , giving it the highest priority for improvement. The job of inter-city bus drivers entails long working hours and requires intense concentration while on duty. Serious accidents are more likely to happen if the driver fails to effectively manage off-duty time or maintain good physical condition. In addition, the driver needs to maintain good health. Human resource (FM3) is ranked in second place with an RPN value of 0.5005 . The possible mistakes related to this include employing drivers with inappropriate personality traits, insufficient risk perception training, and work force shortages leading to excessive overtime shifts. It is recommended that managers should consider the person- 
Table 8 The initial assessment matrix

\begin{tabular}{|c|c|c|c|c|}
\hline Failure mode & $S$ & $O$ & $D$ & $E$ \\
\hline FM1 & $(3.538,3.948,4.388)$ & $(2.851,3.210,3.599)$ & $(5.073,5.512,5.952)$ & $(4.027,4.466,4.906)$ \\
\hline FM2 & $(5.109,5.550,5.991)$ & $(4.683,5.121,5.559)$ & $(3.686,4.127,4.567)$ & $(3.799,4.226,4.667)$ \\
\hline FM3 & $(6.233,6.677,7.121)$ & $(4.423,4.867,5.311)$ & $(2.347,2.713,3.109)$ & $(4.469,4.913,5.357)$ \\
\hline FM4 & $(4.793,5.228,5.663)$ & $(3.069,3.427,3.814)$ & $(2.763,3.165,3.597)$ & $(4.824,5.258,5.693)$ \\
\hline FM5 & $(5.636,6.074,6.512)$ & $(2.496,2.841,3.232)$ & $(1.592,1.881,2.185)$ & $(3.753,4.176,4.614)$ \\
\hline FM6 & $(5.016,5.454,5.892)$ & $(4.088,4.496,4.934)$ & $(3.413,3.7924 .186)$ & $(3.440,3.864,4.302)$ \\
\hline FM7 & $(4.543,4.978,5.413)$ & $(2.983,3.388,3.823)$ & $(2.323,2.696,3.084)$ & $(2.974,3.393,3.829)$ \\
\hline FM8 & $(5.131,5.572,6.013)$ & $(3.706,4.131,4.572)$ & $(2.207,2.602,3.043)$ & $(2.405,2.817,3.260)$ \\
\hline FM9 & $(4.768,5.200,5.633)$ & $(3.530,3.932,4.364)$ & $(2.343,2.745,3.177)$ & $(2.867,3.252,3.637)$ \\
\hline FM10 & $(4.730,5.157,5.584)$ & $(3.614,3.979,4.358)$ & $(1.853,2.172,2.506)$ & $(2.851,3.216,3.595)$ \\
\hline FM11 & $(4.559,4.980,5.415)$ & $(3.213,3.618,4.053)$ & $(2.379,2.752,3.140)$ & $(2.060,2.389,2.732)$ \\
\hline FM12 & $(6.261,6.694,7.126)$ & $(4.860,5.292,5.725)$ & $(4.375,4.807,5.240)$ & $(3.729,4.147,4.580)$ \\
\hline FM13 & $(4.377,4.812,5.247)$ & $(3.416,3.836,4.271)$ & $(3.510,3.916,4.352)$ & $(2.592,2.965,3.353)$ \\
\hline FM14 & $(5.440,5.869,6.299)$ & $(4.438,4.867,5.297)$ & $(3.436,3.835,4.265)$ & $(2.974,3.328,3.713)$ \\
\hline FM15 & $(5.100,5.530,5.959)$ & $(3.264,3.664,4.093)$ & $(2.559,2.988,3.418)$ & $(2.672,3.072,3.502)$ \\
\hline FM16 & $(4.963,5.395,5.827)$ & $(3.217,3.649,4.082)$ & $(2.99493 .397,3.829)$ & $(2.337,2.755,3.187)$ \\
\hline FM17 & $(6.057,6.493,6.928)$ & $(3.231,3.667,4.102)$ & $(3.840,4.276,4.711)$ & $(3.198,3.589,3.979)$ \\
\hline FM18 & $(6.133,6.576,7.020)$ & $(4.436,4.879,5.323)$ & $(2.615,2.998,3.397)$ & $(3.105,3.533,3.977)$ \\
\hline FM19 & $(5.677,6.121,6.565)$ & $(4.388,4.832,5.275)$ & $(2.949,3.334,3.733)$ & $(2.876,3.289,3.733)$ \\
\hline FM20 & $(5.874,6.312,6.750)$ & $(4.245,4.683,5.121)$ & $(1.707,2.087,2.525)$ & $(2.648,3.086,3.524)$ \\
\hline
\end{tabular}

Table 9 The ranking results from $Z$-WASPAS

\begin{tabular}{lllll}
\hline Failure mode & $\otimes S Q_{i}$ & $\otimes P Q_{i}$ & $\varphi_{i}$ & Rank \\
\hline FM1 & $(0.338,0.429,0.531)$ & $(0.430,0.422,0.422)$ & 0.4269 & 11 \\
FM2 & $(0.391,0.491,0.601)$ & $(0.492,0.486,0.488)$ & 0.4900 & 4 \\
FM3 & $(0.414,0.513,0.621)$ & $(0.493,0.485,0.485)$ & 0.5005 & 2 \\
FM4 & $(0.355,0.445,0.545)$ & $(0.444,0.434,0.430)$ & 0.4408 & 9 \\
FM5 & $(0.339,0.421,0.512)$ & $(0.396,0.380,0.371)$ & 0.4018 & 16 \\
FM6 & $(0.369,0.462,0.566)$ & $(0.465,0.456,0.455)$ & 0.4604 & 8 \\
FM7 & $(0.307,0.389,0.483)$ & $(0.388,0.377,0.374)$ & 0.3848 & 18 \\
FM8 & $(0.328,0.414,0.512)$ & $(0.401,0.392,0.392)$ & 0.4047 & 15 \\
FM9 & $(0.321,0.406,0.502)$ & $(0.403,0.393,0.390)$ & 0.4009 & 17 \\
FM10 & $(0.311,0.391,0.481)$ & $(0.384,0.370,0.363)$ & 0.3820 & 19 \\
FM11 & $(0.297,0.376,0.467)$ & $(0.372,0.360,0.355)$ & 0.3697 & 20 \\
FM12 & $(0.450,0.556,0.672)$ & $(0.551,0.546,0.549)$ & 0.5527 & 1 \\
FM13 & $(0.324,0.411,0.509)$ & $(0.414,0.405,0.403)$ & 0.4092 & 14 \\
FM14 & $(0.383,0.477,0.582)$ & $(0.474,0.465,0.464)$ & 0.4724 & 6 \\
FM15 & $(0.332,0.418,0.515)$ & $(0.412,0.402,0.399)$ & 0.4115 & 12 \\
FM16 & $(0.329,0.416,0.514)$ & $(0.411,0.402,0.400)$ & 0.4104 & 13 \\
FM17 & $(0.401,0.498,0.604)$ & $(0.490,0.481,0.479)$ & 0.4908 & 3 \\
FM18 & $(0.395,0.491,0.597)$ & $(0.473,0.465,0.465)$ & 0.4795 & 5 \\
FM19 & $(0.380,0.474,0.580)$ & $(0.465,0.456,0.456)$ & 0.4668 & 7 \\
FM20 & $(0.357,0.447,0.548)$ & $(0.415,0.407,0.408)$ & 0.4286 & 10 \\
\hline
\end{tabular}


ality traits of the drivers and strengthen training systems for worker recruitment. Another recommendation is to change the salary structure so that the driver is not driving in poor mental condition and is regularly paid for overtime. Driver's decision-making error (FM17) and administrative negligence (FM2) are ranked in third and fourth place. Driver decisionmaking errors include inappropriate response to emergencies and poor judgment of the direction and status of oncoming vehicles. Improper operation or behavior are the main causes for the above failures. Managers should provide good training and educate drivers about the importance of following the standard operating procedures. A monitoring system or warnings about excessive speed might be possible enforcement solutions. Administrative negligence can include governmental negligence in implementing the relevant traffic rules and guidelines for supervision and management responsibilities, and not ensuring that transportation companies conduct safety training and are managed well. Bus companies tend to disregard regular employee training to save on costs and capital investment for vehicles maintenance and replacement. It is recommended that the relevant government departments should strengthen safety regulations and subsidy policies, by requiring bus companies to build safety management systems and/or offering subsidies for maintenance of equipment and vehicle replacement. In addition, government departments could request bus companies to hold training seminars to strengthen driver safety knowledge and awareness. "Driver operating error (FM18)" and "poor mental state (FM14)" ranked fifth and sixth. Driver mistakes can include overly rapid acceleration or deceleration, improper lane changes, failure to maintain safe driving distances, etc. Poor mental state can include personal attitudes, not caring about safety, driver fatigue, mental fatigue, and so on. Bad moods also increase the chance of accidents. Therefore, these human error factors are also the key failure modes that decision makers need to pay attention to and improve.

\section{Model comparison}

In this section, a variety of methods are compared and discussed starting with three weighting methods, which include AHP, the Full Consistency Method (FUCOM) [37], and BWM. These three methods are all based on the use of pairwise comparisons to derive the criteria weights. The AHP requires the largest number of pairwise comparisons, which is $n(n-1) / 2$ followed by FUCOM and BWM with $n-1$ and $2 n-3$, respectively. The higher the number of pairwise comparisons, the less consistent results may result. Obviously, FUCOM's consistency performance is the best. However, although BWM offers slightly weaker consistency results, its input data are comprised of two conceptually different vectors (BO and $\mathrm{OW}$ vectors), which can more accurately reflect the expert's evaluation. The three methods were tested and the weights of the risk factors found to be only slightly different. The importance ranking remained the same $S \succ D$ $\succ E \succ O$ for all three methods, and there was no effect on the ranking of the failure modes. The results indicated that all three methods are applicable but the BWM method was selected for case analysis in this study because it can reflect the experts' assessment information from two different perspectives.

A comparison of six alternative ranking methods was performed to illustrate the practicality of the proposed integration model for the ranking of failure modes. The risk factor weight settings for these six models are all based on those in Table 7, to ensure consistency. Model 1, Z-WASPAS, is the method proposed in this study, model 2 is the original FMEA calculation method, where the values of $S, O, D$, and $E$ are multiplied. In addition, four common MCDM methods are included in the model comparison, $Z$-number-based Additive Ratio ASsessment (Z-ARAS), Z-TOPSIS, $Z$-VIKOR, and $Z$ number-based grey relational analysis ( $Z$-GRA). $Z$-numbers are introduced into all six models to reflect the uncertainty and confidence level of the experts. Table 10 shows the failure mode ranking results for the six models. Obviously, F12 is ranked the highest risk failure mode by all models. However, the ranking of the other failure modes is inconsistent, as shown in Fig. 3. A further step is carried out using the Spearman correlation coefficient to identify the correlation in the ranking results obtained with the six methods. Z-WASPAS, the original FMEA, $Z$-ARAS, and Z-GRA have higher correlation coefficients (greater than 0.9), as shown in Table 11. On the other hand, Z-TOPSIS and Z-VIKOR are based on the concept of distance, thus, their results are different from the $Z$-WASPAS results. Although we cannot prove that the proposed $Z$-WASPAS method offers excellent results, this method is intuitive and simple to implement, which helps FMEA experts to analyze and find the root causes in real circumstances. In addition, one of the calculation parameters of $Z$-WASPAS is based on the original concept of FMEA multiplication which also corresponds to the FMEA calculation process.

The risk factor $E$ is included in our proposed model, which is significantly different from the conventional FMEA (only three risk factors $S, O$, and $D$ ) calculation. Figure 4 shows the difference between $E$ and without $E$. For example, FM3 is ranked 2nd and 6th, respectively, which will affect the improving strategies of decision-makers. In addition to FM3, there are also many failure mode sequencing differences. In practice, risk costs are generally divided into three categories, that is, tangible costs, intangible costs, and prevention or control costs of risk losses. In the transportation system, the occurrence of risk accidents will cause the loss of the expected economic benefits of the enterprise. This paper proposes HFACS-FMEA for the first time to summarize and analyze the potential failure modes and risks of the inter-city 
Table 10 Ranking results of failure modes for the six models

\begin{tabular}{|c|c|c|c|c|c|c|c|c|c|c|c|c|}
\hline & \multicolumn{2}{|c|}{ Z-WASPAS } & \multicolumn{2}{|c|}{ Original FMEA } & \multicolumn{2}{|c|}{$Z$-ARAS } & \multicolumn{2}{|c|}{$Z$-TOPSIS } & \multicolumn{2}{|c|}{$Z$-VIKOR } & \multicolumn{2}{|c|}{$Z$-GRA } \\
\hline & $\varphi_{i}$ & Rank & $\mathrm{RPN}_{i}$ & rank & $K_{\mathrm{i}}$ & Rank & $c c_{i}$ & Rank & $Q_{\mathrm{i}}$ & Rank & $r_{i}$ & Rank \\
\hline FM1 & 0.427 & 11 & 312.864 & 9 & 0.048 & 11 & 0.245 & 19 & 0.653 & 20 & 0.825 & 12 \\
\hline FM2 & 0.490 & 4 & 495.901 & 2 & 0.055 & 4 & 0.411 & 7 & 0.530 & 7 & 0.881 & 5 \\
\hline FM3 & 0.501 & 2 & 433.910 & 3 & 0.057 & 2 & 0.510 & 2 & 0.498 & 3 & 0.926 & 2 \\
\hline FM4 & 0.441 & 9 & 299.008 & 10 & 0.050 & 10 & 0.328 & 11 & 0.573 & 12 & 0.840 & 10 \\
\hline FM5 & 0.402 & 16 & 136.155 & 19 & 0.047 & 12 & 0.359 & 10 & 0.575 & 13 & 0.834 & 11 \\
\hline FM6 & 0.460 & 8 & 360.114 & 6 & 0.052 & 8 & 0.366 & 9 & 0.552 & 8 & 0.852 & 9 \\
\hline FM7 & 0.385 & 18 & 154.788 & 17 & 0.044 & 19 & 0.247 & 18 & 0.618 & 18 & 0.789 & 19 \\
\hline FM8 & 0.405 & 15 & 169.639 & 16 & 0.046 & 15 & 0.315 & 13 & 0.571 & 10 & 0.817 & 14 \\
\hline FM9 & 0.401 & 17 & 183.092 & 15 & 0.046 & 17 & 0.279 & 15 & 0.597 & 15 & 0.805 & 16 \\
\hline FM10 & 0.382 & 19 & 143.673 & 18 & 0.044 & 18 & 0.260 & 17 & 0.607 & 16 & 0.795 & 18 \\
\hline FM11 & 0.370 & 20 & 118.878 & 20 & 0.042 & 20 & 0.237 & 20 & 0.625 & 19 & 0.780 & 20 \\
\hline FM12 & 0.553 & 1 & 706.614 & 1 & 0.062 & 1 & 0.587 & 1 & 0.430 & 1 & 0.961 & 1 \\
\hline FM13 & 0.409 & 14 & 214.885 & 11 & 0.046 & 16 & 0.263 & 16 & 0.616 & 17 & 0.804 & 17 \\
\hline FM14 & 0.472 & 6 & 365.714 & 4 & 0.053 & 6 & 0.417 & 6 & 0.520 & 6 & 0.872 & 7 \\
\hline FM15 & 0.412 & 12 & 186.542 & 13 & 0.047 & 13 & 0.318 & 12 & 0.572 & 11 & 0.818 & 13 \\
\hline FM16 & 0.410 & 13 & 184.661 & 14 & 0.047 & 14 & 0.309 & 14 & 0.580 & 14 & 0.814 & 15 \\
\hline FM17 & 0.491 & 3 & 365.275 & 5 & 0.056 & 3 & 0.495 & 3 & 0.474 & 2 & 0.901 & 4 \\
\hline FM18 & 0.480 & 5 & 340.479 & 7 & 0.055 & 5 & 0.479 & 4 & 0.502 & 4 & 0.901 & 3 \\
\hline FM19 & 0.467 & 7 & 325.000 & 8 & 0.053 & 7 & 0.429 & 5 & 0.508 & 5 & 0.875 & 6 \\
\hline FM20 & 0.429 & 10 & 191.174 & 12 & 0.050 & 9 & 0.403 & 8 & 0.554 & 9 & 0.861 & 8 \\
\hline
\end{tabular}

Fig. 3 Ranking results of the six models

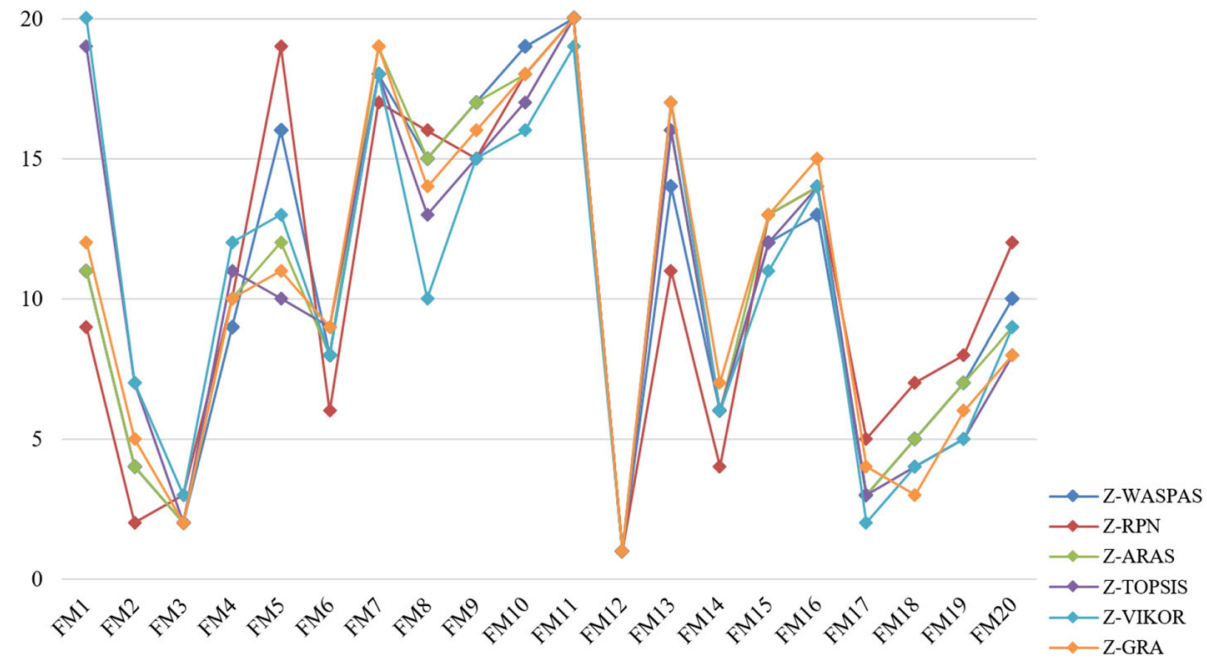

bus accidents. Due to the rising awareness of risk costs management, this study incorporates this concept to make the analysis results closer to practice and more reliable.

\section{Sensitivity analysis}

The most important risk factor is $S$ with a weight value of $(0.381,0.419$ and 0.451$)$. Obviously, it has a significant influence in the overall evaluation system. In this section, we explore whether changes to the weight of risk factor $S$ will affect the overall ranking results of the evaluation system. Sensitivity analysis is conducted to observe whether there will be any significant change in the priority ranking of the failure modes analysis. We changed the value of the weight of $S$ from 0.1 to 0.9 and adjusted the weights of other risk factors proportionally. Since the $Z$-number is comprised of a set of three values, the upper boundary value was used as the basis for adjustment, as shown in Table 12. According to Fig. 5, changing the weights led to a change in the ranking of all failure modes except for FM12, which remained in first 
Table 11 Correlation coefficients between models

\begin{tabular}{lllllll}
\hline & Z-WASPAS & Original FMEA & Z-ARAS & Z-TOPSIS & Z-VIKOR & Z-GRA \\
\hline Z-WASPAS & 1 & 0.956 & 0.980 & 0.895 & 0.875 & 0.956 \\
Z-RPN & 0.956 & 1 & 0.911 & 0.777 & 0.765 & 0.862 \\
Z-ARAS & 0.980 & 0.911 & 1 & 0.928 & 0.893 & 0.988 \\
Z-TOPSIS & 0.895 & 0.777 & 0.928 & 1 & 0.979 & 0.950 \\
Z-VIKOR & 0.875 & 0.765 & 0.893 & 0.979 & 1 & 0.914 \\
Z-GRA & 0.956 & 0.862 & 0.988 & 0.950 & 0.914 & 1 \\
\hline
\end{tabular}

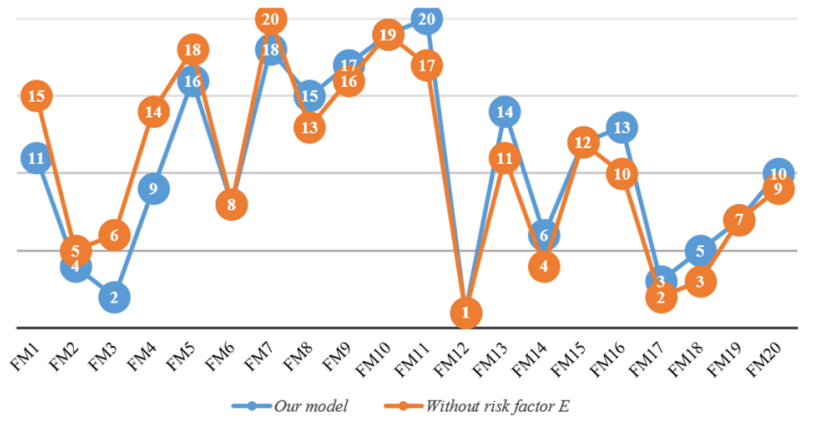

Fig. 4 The difference between $E$ and without $E$

place. This indicates the extreme sensitivity of the other failure modes. This phenomenon indicates that it is necessary to determine the weights of the risk factors, for example by using the $Z$-BWM evaluation method described in this study is an essential step to estimate the weights of the risk factors while conducting a risk assessment.

\section{Conclusions and future work}

This study proposes a new hybrid model for risk assessment regarding inter-city bus transportation. The model improves several shortcomings of the HFACS. First the HFACS framework is used to establish possible failure modes. Then the FMEA is combined with MCDM for risk assessment. $Z$ numbers are used in the analysis in combination with BWM to determine the importance of the risk factors, and finally the Z-WASPAS method is applied to rank the failure modes. The conclusions are summarized below:

1. The results show that severity has the highest weight value, thus, management needs to assign it the first priority for problem solving.

2. The results show that FM12 (personal readiness) is the number one ranked failure mode. Management should prioritize it for improvement.

3. Z-numbers are utilized to deal with the vagueness and uncertainty of expert judgements, allowing consideration of the confidence level and differences in reliability. In addition, to avoid missing information by using linguistic variables while conducting expert survey, the weights of the risk factors and values of failure modes are all fully retained through fuzzy interval values during the calculation process, which makes the evaluation results more reliable.

4. The risk factor of expected cost is added to the risk assessment model and failure modes extended to include external factors in response to real circumstances. Management can adopt more comprehensive strategies for improvement in the safety of inter-city bus service.

This study proposes a hybrid model to effectively identify potential risks before system failure occurs with the aim of eliminating the risk of failure by preventing and improving the risk factors. However, there are some restrictions and suggestions for decision-makers and further research.

1. The assessment of the risk factors by the 10 experts was integrated by an arithmetic mean method. However, due to differences in the area of expertise and degree of experience of each expert, we can also consider giving different weight values or using the multiple attribute group decision-making (MAGDM) method to consider the different weights.

2. The proposed evaluation model can be applied to other types of public transportation, such as railways, ferries, airplanes, subway systems, and the like. In addition, it could be adapted for other industries, for example, for product quality or supplier selection problems in manufacturing.

3. In the past, there have been very few studies in the transportation field that have combined MCDM and FMEA to produce hybrid model. This study focuses on the application of $Z$-numbers combined with BWM and $Z$-WASPAS calculations. This hybrid model can be extended and compared with other MCDM methods, such as TOPSIS, VIKOR, COPRAS, and GRA in the future. In addition, $Z$-numbers can be compared with other fuzzy theories, such as Pythagorean fuzzy sets, spherical fuzzy sets, Fermatean fuzzy sets, etc., to select the most suitable fuzzy theory for each application.

4. This research focuses on ranking the risk factors but assumes that they are independent of each other. It is 

combinations
Table 12 Nine weight

\begin{tabular}{lllll}
\hline & $S$ & $O$ & $D$ & $E$ \\
\hline Run 1 & $(0.084,0.093,0.1)$ & $(0.211,0.258,0.317)$ & $(0.310,0.365,0.422)$ & $(0.245,0.281,0.314)$ \\
Run 2 & $(0.169,0.186,0.2)$ & $(0.190,0.232,0.285)$ & $(0.279,0.328,0.379)$ & $(0.220,0.252,0.282)$ \\
Run 3 & $(0.253,0.279,0.3)$ & $(0.168,0.206,0.252)$ & $(0.247,0.291,0.336)$ & $(0.195,0.223,0.250)$ \\
Run 4 & $(0.338,0.372,0.4)$ & $(0.147,0.179,0.220)$ & $(0.216,0.254,0.293)$ & $(0.170,0.195,0.218)$ \\
Run 5 & $(0.422,0.465,0.5)$ & $(0.125,0.153,0.188)$ & $(0.184,0.216,0.250)$ & $(0.145,0.166,0.186)$ \\
Run 6 & $(0.507,0.558,0.6)$ & $(0.104,0.127,0.155)$ & $(0.152,0.179,0.207)$ & $(0.120,0.138,0.154)$ \\
Run 7 & $(0.591,0.651,0.7)$ & $(0.082,0.100,0.123)$ & $(0.121,0.142,0.164)$ & $(0.095,0.109,0.122)$ \\
Run 8 & $(0.675,0.744,0.8)$ & $(0.061,0.074,0.091)$ & $(0.089,0.105,0.121)$ & $(0.070,0.080,0.090)$ \\
Run 9 & $(0.760,0.837,0.9)$ & $(0.039,0.048,0.059)$ & $(0.057,0.068,0.078)$ & $(0.045,0.052,0.058)$ \\
\hline
\end{tabular}

intended use is not permitted by statutory regulation or exceeds the permitted use, you will need to obtain permission directly from the copyright holder. To view a copy of this licence, visit http://creativecomm ons.org/licenses/by/4.0/.

\section{References}

1. Aboutorab H, Saberi M, Asadabadi M-R, Hussain O, Chang E (2018) ZBWM: the Z-number extension of best worst method and its application for supplier development. Expert Syst Appl 107:115-125

2. Akyuz E (2017) A marine accident analysing model to evaluate potential operational causes in cargo ships. Saf Sci 92:17-25

3. Alvand A, Mirhosseini S-M, Ehsanifar M, Zeigham E, Mohammadi A (2021) Identification and assessment of risk in construction projects using the integrated FMEA-SWARA-WASPAS model under fuzzy environment: a case study of a construction project in Iran. Int J Constr Manag 1-23. (In Press)

Fig. 5 Ranking results from the nine sensitivity analyses

suggested that DEMATEL can be introduced to consider the interdependence of the risk factors, to determine the degree of mutual influence as laid out in a causal relationship diagram.

\section{Declarations}

Conflict of interest All authors declare that they have no conflict of interests.

Ethical approval The authors of this article did not perform any studies with humans or animals.

Open Access This article is licensed under a Creative Commons Attribution 4.0 International License, which permits use, sharing, adaptation, distribution and reproduction in any medium or format, as long as you give appropriate credit to the original author(s) and the source, provide a link to the Creative Commons licence, and indicate if changes were made. The images or other third party material in this article are included in the article's Creative Commons licence, unless indicated otherwise in a credit line to the material. If material is not included in the article's Creative Commons licence and your
4. Arabian-Hoseynabadi H, Oraee H, Tavner P-J (2010) Failure modes and effects analysis (FMEA) for wind turbines. Int J Electr Power Energy Syst 32(7):817-824

5. Badalpur M, Nurbakhsh E (2021) An application of WASPAS method in risk qualitative analysis: a case study of a road construction project in Iran. Int J Constr Manag 21(9):910-918

6. Beanland V, Sellbom M, Johnson A-K (2014) Personality domains and traits that predict self-reported aberrant driving behaviours in a Southeastern US University Sample. Accid Anal Prev 72:184-192

7. Boral S, Howard I, Chaturvedi S-K, McKee K, Naikan V-N-A (2020) An integrated approach for fuzzy failure modes and effects analysis using fuzzy AHP and fuzzy MAIRCA. Eng Fail Anal 108:104195

8. Celik M, Cebi S (2009) Analytical HFACS for investigating human errors in shipping accidents. Accid Anal Prev 41(1):66-75

9. Chen X, Liu X, Qin Y (2019) An extended HFACS based risk analysis approach for human error accident with interval type-2 fuzzy sets and prospect theory. J Intell Fuzzy Syst 37(6):8381-8395

10. Chiu M-C, Hsieh M (2016) Latent human error analysis and tenance tasks. Appl Ergon 54:136-147

11. Cohen T-N, WiegmannShappell D-AS-A (2015) Evaluating the reliability of the human factors analysis and classification system. Aerosp Med Hum Perform 86(8):728-735

12. Di Pasquale V, Miranda S, Iannone R, Riemma S (2015) A simulator for human error probability analysis (SHERPA). Reliab Eng Syst Saf 139:17-32

13. Ergai A, Cohen T, Sharp J, Wiegmann D, Gramopadhye A, Shappell $S$ (2016) Assessment of the human factors analysis and efficient improvement strategies by fuzzy TOPSIS in aviation main- 
classification system (HFACS): intra-rater and inter-rater reliability. Saf Sci 82:393-398

14. Gugaliya A, Boral S, Naikan V-N-A (2019) A hybrid decision making framework for modified failure mode effects and criticality analysis: A case study on process plant induction motors. Int J Qual Reliab Manag 36(8):1266-1283

15. Hale A, Walker D, Walters N, Bolt H (2012) Developing the understanding of underlying causes of construction fatal accidents. Saf Sci 50(10):2020-2027

16. Havle C-A, Kılıç B (2019) A hybrid approach based on the fuzzy AHP and HFACS framework for identifying and analyzing gross navigation errors during transatlantic flights. J Air Transp Manag 76:21-30

17. Hsieh MC, Chiang P-Y, Lee Y-C, Wang E-M-Y, Kung W-C, Hu Y-T, Hsieh H-C (2021) An investigation of human errors in medication adverse event improvement priority using a hybrid approach. Healthc (Amst) 9(4):442-457

18. Hsieh M-C, Wang E-M-Y, Lee W-C, Li L-W, Hsieh C-Y, Tsai W, Liu T-C (2018) Application of HFACS, fuzzy TOPSIS, and AHP for identifying important human error factors in emergency departments in Taiwan. Int J Ind Ergon 67:171-179

19. Jiang W, Xie C, Wei B, Tang Y (2018) Failure mode and effects analysis based on Z-numbers. Intell Autom Soft Comput 24(1):165-172

20. Jiang W, Zhang Z, Deng X (2019) A novel failure mode and effects analysis method based on fuzzy evidential reasoning rules. IEEE Access 7:113605-113615

21. Karthick M, Robert T-P, Kumar C-S (2020) HFACS-based FAHP implementation to identify critical factors influencing human error occurrence in nuclear plant control room. Soft Comput 24(21):16577-16591

22. LAARAJ N, JAWAB F (2018) Road accident modeling approaches: literature review. In: 2018 international colloquium on logistics and supply chain management (LOGISTIQUA), pp $188-193$

23. Leveson $\mathrm{N}$ (2004) A new accident model for engineering safer systems. Saf Sci 42(4):237-270

24. Liu H-C, Chen X-Q, Duan C-Y, Wang Y-M (2019) Failure mode and effect analysis using multi-criteria decision making methods: a systematic literature review. Comput Ind Eng 135:881-897

25. Liu H-C, Liu L, Liu N, Mao L-X (2012) Risk evaluation in failure mode and effects analysis with extended VIKOR method under fuzzy environment. Expert Syst Appl 39(17):12926-12934

26. Liu H-C, Wang L-E, You X-Y, Wu S-M (2019) Failure mode and effect analysis with extended grey relational analysis method in cloud setting. Total Qual Manag Bus Excell 30(7-8):745-767

27. Liu R, Cheng W, Yu Y, Xu Q, Jiang A, Lv T (2019) An impacting factors analysis of miners' unsafe acts based on HFACS-CM and SEM. Process Saf Environ Prot 122:221-231

28. Li W-C, Harris D, Yu C-S (2006) Routes to failure: analysis of 41 civil aviation accidents from the Republic of China using the human factors analysis and classification system. Accid Anal Prev 40(2):426-434

29. Li Y, Guldenmund F-W (2018) Safety management systems: a broad overview of the literature. Saf Sci 103:94-23

30. Lo H-W, Liou J-J (2018) A novel multiple-criteria decisionmaking-based FMEA model for risk assessment. Appl Soft Comput 73:684-696

31. Lo H-W, Liou J-J, Huang C-N, Chuang Y-C (2019) A novel failure mode and effect analysis model for machine tool risk analysis. Reliab Eng Syst Saf 183:173-183

32. Mohammed A-A, Ambak K, Mosa A-M, Syamsunur D (2019) A review of traffic accidents and related practices worldwide. Open Transp J 13(1):65-83
33. Mohsen O, Fereshteh N (2017) An extended VIKOR method based on entropy measure for the failure modes risk assessment-a case study of the geothermal power plant (GPP). Saf Sci 92:160-172

34. Newnam S, Goode N (2015) Do not blame the driver: a systems analysis of the causes of road freight crashes. Accid Anal Prev 6:141-151

35. O'Connor P (2008) HFACS with an additional layer of granularity: validity and utility in accident analysis. Aerosp Med Hum Perform 79(6):599-606

36. Olsen N-S (2011) Coding ATC incident data using HFACS: intercoder consensus. Saf Sci 49(10):1365-1370

37. Pamučar D, Stević Ž, Sremac S (2018) A new model for determining weight coefficients of criteria in mcdm models: full consistency method (fucom). Symmetry 10(9):393

38. Peden M, Scurfield R, Sleet D, Mohan D, Hyder A-A, Jarawan E, Mathers C (2004) World report on road traffic injury prevention. World Health Organization, Geneva, pp 69-94

39. Rasmussen J (1997) Risk management in a dynamic society: a modelling problem. Saf Sci 27(2-3):183-213

40. Reason J (1990) Human error. Cambridge University Press, Cambridge

41. Reinach S, Viale A (2006) Application of a human error framework to conduct train accident/incident investigations. Accid Anal Prev 38(2):396-406

42. Rezaei J (2015) Best-worst multi-criteria decision-making method. Omega 53:49-57

43. Rostamabadi A, Jahangiri M, Zarei E, Kamalinia M, Banaee S, Samaei M-R (2019) A novel fuzzy Bayesian network-HFACS (FBN-HFACS) model for analyzing human and organization factors (HOFs) in process accidents. Process Saf Environ Prot 132:59-72

44. Sarıalioğlu S, Uğurlu Ö, Aydın M, Vardar B, Wang J (2020) A hybrid model for human-factor analysis of engine-room fires on ships: HFACS-PV\&FFTA. Ocean Eng 217:107992

45. Shappell S-A, Wiegmann D-A (2000) The human factors analysis and classification system-HFACS. University of Illinois Institute of Aviation, Oklahoma City

46. Stanton N-A, Salmon P-M (2009) Human error taxonomies applied to driving: a generic driver error taxonomy and its implications for intelligent transport systems. Saf Sci 47(2):227-237

47. Van Elslande P (2003) Erreurs de conduite et besoins d'aide: une approche accidentologique en ergonomie. Trav Hum 66(3):197-224

48. Wang X, Yu H, Nie C, Zhou Y, Wang H, Shi X (2019) Road traffic injuries in China from 2007 to 2016: the epidemiological characteristics, trends and influencing factors. Peer J 7:11-25

49. Wei S-X, Sui Y-C, Chen Y-C (2014) Research into the human errors evaluation method of flight accidents based on HFACS. Aeron Comput Tech 44(2):50-53

50. Wiegmann D-A, Shappell S-A (2003) A human error approach to aviation accident analysis: the human factors analysis and classification system. Ashgate Great Britain. https://trove.nla.gov.au/ version/28337285. Accessed 18 Mar 2021

51. Yaacob N-F-F, Rusli N, Bohari S-N (2018) A review analysis of accident factor on road accident cases using Haddon matrix approach. In: Proceedings of the second international conference on the future of ASEAN (ICoFA) 2017-2, pp 55-65

52. Zadeh L-A (2011) A note on Z-numbers. Inf Sci 181(14):2923-2932

53. Zarei E, Yazdi M, Abbassi R, Khan F (2019) A hybrid model for human factor analysis in process accidents: FBN-HFACS. J Loss Prev Process Ind 57:142-155

54. Zhou Z-C (2019) Research on the Estimation of Road Traffic Accident Cost. Institute of Transportation, Ministry of Transportation, Taiwan, R.O.C. MOTC-IOT-101-SEB010, pp 139-140 
55. Zhang Y, Jing L, Sun C, Fang J, Feng Y (2019) Human factors related to major road traffic accidents in China. Traffic Inj Prev 20(8):1-5
56. Zhang Y, Liu T, Bai Q, Shao W, Wang Q (2018) New systemsbased method to conduct analysis of road traffic accidents. Transp Res Part F Traffic Psychol Behav 54:96-109

Publisher's Note Springer Nature remains neutral with regard to jurisdictional claims in published maps and institutional affiliations. 